\title{
Communicating with the dying
}

\section{J Michael Wilson Department of Theology, University of Birmingham}

Telling a patient that the outcome of his illness is not good, or even hopeless, requires sensitivity and the ability to communicate with him in the setting of a hospital which is an unnatural environment divorced from family and friends. It is a task which must be taught and learned by doctors and nurses.

In hospital it is too often assumed that the communication of a bad prognosis is a controlled situation in which it is possible to convey serious news to the family but to withhold it from the patient. This idea must now be regarded as the worst possible form of communication. We do not just pass information to one another, we also convey without words our attitudes and feelings to one another.

\section{Silent signals}

Non-verbal signals are very subtle: they are socially learnt and can be as confusing to a foreigner as an unknown language. We watch a person's face and observe slight changes of expression in the eyes or mouth. We note the making or evasion of eye contact and whether the movement is natural or forced. We unconsciously see the embarrassed wave of a hand and hear a change in the timbre of the voice. In ways such as this we convey not only facts but feelings and what we communicate is not always under our direct control.

It is incredible that patients in a hospital ward can still be moved to the bed nearest the door or to a screened corner bed (often for good reasons) but are not supposed to recognize the implications. Patients notice when their questions are evaded. They notice when reassurance is not given because we are so quick to give it to those to whom we can. A change in the consultant's visiting pattern, the loss of interest in a patient by his doctor, these are signals to be understood. If further you believe that a 'group mind' exists then you will see how the attitudes of those surrounding a patient and the whole social context may shout its particular messages: and conflicting voices may add to a patient's suffering.

It is therefore probable that most patients do in fact know when their prognosis is bad. We cannot decide (for example) whether or not to tell a patient about the nature of a fatal illness. We cannot help telling because of the way we 'read' one another But whether patients want to bring that knowledges to conscious consideration, to utter it (to 'outer it'),. to share it and discuss it with others, that is $\mathrm{a} \overrightarrow{\vec{\omega}}$ different matter.

For example, a medical student of 30 with secondary carcinoma in the ovaries and peritoneum. actually read the pathology report in her own case. notes: yet she accepted the consultant's reassurance $\vec{\infty}$ that there was no malignancy.

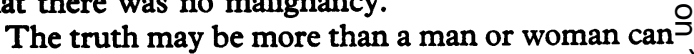
bear. Although words are the obvious means of communicating, words are notoriously insufficient.을 T S Eliot (1935) wrote:

Words after speech, reach

Into the silence...

... Words strain,

Crack and sometimes break, under the burden,

Under the tension, slip, slide, perish,

Decay with imprecision, will not stay in place,

Will not stay still ....

Anyone who has tried to communicate a badf prognosis will recognize this verbal limitation: 'Words strain, crack and sometimes break ... will not stay in place, will not stay still'. But com munication is two-way, and perhaps we should talk of 'working together' towards the point where weo can both face the truth about a situation. For the situation is not just the patient's alone: 'Any man's death diminishes me because $I$ am involved in mankinde' (Fohn Donne, ed J Hayward, 1929)옹 Mutuality is not merely essential, it is a fact.

\section{Communication is mutual}

We tend to speak of communication (and my title suggests it) in a one-sided way. We communicate bad prognosis (or a good one for that matter) to them. But communication is mutual - the very word communication means something more like a dance together between partners responding to one another. There are no rehearsals, every com 0 munication is new.

There are no blueprints for an ideal way to make difficult communication: there are no situations toे be legislated for. There are people to be talked to people to work with, situations to be lived. People are more important than principles. The whole business of 'communicating a bad prognosis' is 
highly interpersonal encounter. You do not hand someone a communication on a plate as if it had come from outer space - the communicator is part of the message. We therefore communicate what we have come to think and feel in the face of our own crises - hope or despair. The patient also is not just a passive receiver of heavy tidings: he too is a human being who may react with anger or hysteria, behave with courage or cowardice, hope or despair: he is a person, an agent, with responsibility for making decisions, for helping to make a good recovery. It is often said: 'It's not what happens to you that matters, it's what you make of it'. And we communicate what we ourselves are making of it - it is not just the patient who is dying, we all are.

It can therefore be misleading to speak of communicating a bad prognosis. There is a value judgment implicit in calling a situation bad. And it is not a matter of communicating something good or bad, but of communicating truly. Most communications contain good and bad, light and shadow, joy and sorrow. But the point is, is it true? Take this example:

'Truth, yes. This is one of our big difficulties. There has been so much covering up of the bad, not being able to speak about the bad, that now people no longer react to truth when they hear it. I remember a patient who had his leg amputated. He gradually went down and down, although the doctor could find no medical reason for his deterioration. In spite of this it was becoming increasingly obvious that he was dying. I asked him, "Are you expecting to die?" He said "Yes". I said, "Well it looks as if you're going to, but the only reason you're going to is you've decided to. There's no physical reason why you should, but you certainly will because you've decided that that's what's going to happen. Why have you decided that you are going to die?" And he told me. The doctor had told two other men in the ward who'd had amputations that they were perfectly all right and would be out in a few weeks. Both died. The doctor said exactly the same thing to him: therefore he had been told he was going to die. It is very difficult when one is covering up on one side to be able to tell the wholeness of truth on any other.' (Marteau, 1970).

I think sometimes we become so complicated about how to relate to someone correctly, or what to tell and what not to tell, that we stultify people's natural gifts for talking to one another.

\section{Listen to the patient}

Part of the art is not giving so much attention to what we would like to communicate as listening to what the patient wants to communicate to us whether verbally or non-verbally. It makes all the difference whether you stand over a patient in a white coat or discard the uniform and sit on the patient's level in a chair: whether you advance upon the patient with a retinue, or none: whether you set out 'to communicate a bad prognosis' or sit down and say 'I expect you'll be wanting to ask me some questions'. The professional who operates from his position of strength may make people afraid of him. You can always stifle a patient's questions if you want to avoid them. On the other hand if we are so approachable, will we ever get through the work? I suggest we must aim at the distinction: we are to be at the disposal of others but not at their mercy.

I do not believe the suggestion of the Cohen Report, that a 'personal doctor' be appointed to ensure proper communication with patients, is an answer that commends itself to most doctors. It dooms the rest of us to becoming technicians. Surely any member of the hospital team, however humble, must be able to talk to patients and answer questions as far as their ability goes and feel that the rest of the team will support them.

\section{A bad prognosis is a part of living}

Any conversation about a prognosis is part of a process in the life of a patient, and needs to be seen within the context of his family and social life. We are too apt to see patients in isolation - but a separate patient is a hospital artefact. I am aware of the general reluctance to communicate a bad prognosis to a patient for fear of his losing morale - I have shared such reluctance: I have for years acted upon it. But I do not now believe this to be in the patient's or his family's best interests. When my first wife died of carcinoma we had together lived through an illness of six years' duration, and shared the knowledge of its nature from the first operation. You have to know what you are up against if you are to make anything out of it. My eldest daughter was 14 when she first took a term off school to learn to look after a family of four brothers so that she might later be able to take over. This is the kind of context within which the communication of a bad $D$ prognosis has to be made. Knowledge of the facts may be vital if a creative response is to be made to a $N$ situation. Withholding information may neuter not only the patient but the family as well. Withholding facts can divorce a husband and wife from one $\omega$ another. Some perhaps want it that way, at any rate at first: ultimately I think few do.

On the other hand in a long and unpredictable illness like Parkinson's disease it is not kind to ? burden people with possible complications that may never arise. This only serves to emphasize that communication is mutual and often depends upon a continuing relationship.

A hospital is therefore a peculiarly difficult $\bar{\sigma}$ context within which to communicate truly. When a prognosis is bad, it is at this moment that a man needs to belong and feel that he belongs to his 
family, friends, and humanity. Hospital staff are often afraid of upsetting a patient because the open expression of feelings arouses their own anxiety. A patient might have hysterics or shout in anger or rebellion. A patient who receives news about the likelihood of his dying may be shocked in the same way that a bereaved person is shocked. Open expression of feeling is by no means undesirable, but it is more easily and naturally dealt with at home where people whom the patient trusts surround him. It is often said that it is cruel to destroy a patient's hope (even a false hope?): that a patient may go to pieces when faced with the knowledge of his own impending death.

\section{'True dealing' of man with man}

Communicating the truth depends upon 'true dealing' of man with man: it is a personal transaction which springs from a personal relationship of trust. You can't just 'switch on' true dealing for the benefit of a patient. It is something that the staff are or are not themselves trying to live in their relationships as colleagues. And if we do not deal truly with our families and friends, again we cannot switch it on just for colleagues. Only those who are prepared to see a patient through, professionally and humanly, can truly communicate a bad prognosis, because they are in themselves prepared to take one another on for better or for worse. Under these kinds of circumstances patients do not commonly go to pieces. At present we have noted a tendency in hospital to isolate a patient whereas his great need is to be affirmed as a person who belongs in terms of family, friends, family doctor, and his own home context. It is in this context that he is supported sufficiently to face reality. In other words, a man must be helped to be fully himself (a self-inrelationship) if he is to be free to know the truth about himself - a truth which he cannot discover in isolation but only in relationship. This discovery about himself is only one part of the family's discovery of the truth about themselves in their common situation with him. Communication is the very stuff of being human. The Xhosa people say: 'A man is a man by reason of other men'.

\section{Learning to communicate in hospital}

There are important implications in what I have written for the education of doctors and nurses. I have assumed that it is as important to acquire skill in human relationships as in materia medica. It is therefore necessary to take seriously a student's personal growth towards maturity and his or her ability to make and sustain personal relationships both with colleagues and patients. The research of Revans (1964 and 1970) has indicated that communication between staff is an important factor in morale which, for example, influences patients' recovery rates as well as sickness rates among $\stackrel{1}{2}$ student nurses. Medical and nurse training schools $m$ have much to learn here from the system of supervised placement work used in the training of social ? workers and clergy.

Education for communication is not so much a matter of introducing a new lecture course into the syllabus, as taking advantage of existing clinical $\frac{\bar{\sigma}}{\bar{D}}$ opportunities. In the training of nurses, the $\frac{\overrightarrow{ }}{\vec{\alpha}}$ increase in the number of clinical teachers on the $\varnothing$ wards means that, given the courage, the whole is life of the ward can be used as learning material. Is $\vec{\circ}$ it more important to reprimand a student nurse for making a mistake or that she should learn from it? $\vec{\omega}$ Kübler-Ross (1970) has shown how seminars with dying patients may be used to deepen the sensitivity of both students and staff to their own needs and feelings as well as to those of their patients.

The work of Abercrombie (1969) with medical $\vec{\infty}$

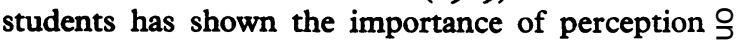
in our communication. Different professions in hospital see situations quite differently, and $>$ patients from outside hospital may find staff attitudes quite foreign. It is important for some $\vec{\varphi}$ basic studies, such as those of human growth and ov development, to be made together in interprofessional classes. Group dynamics could also be a means to discovering the ways in which we actually do or do not communicate. Even simple teaching techniques like role-playing are not used as much $\frac{0}{\mathbb{D}}$ as they could be. And the rich resources of novels $\cong$ and poetry are not to be forgotten.

Our apprenticeship as students or in junior posts 3 gives us a chance to seek experience. Traditionally a consultant or registrar takes a junior doctor with him when dealing with a patient or a family. So we

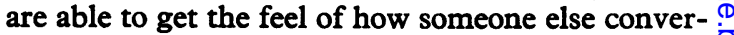
ses in a situation of stress. At this point a certain humility comes in. You can take a student to give an injection and say 'this is how it is done'. But you $\frac{1}{3}$ cannot do that with human communications. You can go together as learners, one experienced the $\frac{5}{5}$ other inexperienced, into a situation which is $\frac{7}{0}$ always new and be willing to discuss it together afterwards. The consultant may have more experi- N ence than his student but his student may be gifted $N$ with a greater sensitivity.

It is in the clinical situation that we learn to speak $\tilde{\omega}$ with our patients and colleagues about illness, handicap, and death. These are conversations in 0 which we can never be merely objective, for we $\mathbb{D}$ know ourselves to be both vulnerable and mortal. Our struggle to develop professionally is one part of our growth towards human maturity: and in $\frac{O}{D}$ learning to communicate truly, we are inevitably $\cong$ exposed as human beings. Giving service to one $\stackrel{\perp}{\perp}$ another is an outward and visible sign of communicating ourselves to one another. But if giving 8 service becomes a substitute for the human transaction, then we dehumanise one another. Michel 
Quoist (197I) wrote: 'A person's greatness is to be measured by his/her capacity for communion with others.'

\section{References}

Abercrombie, M L J (1969). The Anatomy of fudgement. Great Britain: Pelican.

Eliot, T S (1935). Burnt Norton in The Complete Poems and Plays of TS Eliot (1959 edition), $\mathrm{p}$ 175. Faber and Faber, London.

Hayward, J (1929). Ed fohn Donne, Meditation XVII from Devotions upon Emergent Occasions, p 538. Nonesuch Press, London.

Kübler-Ross, E (1970). On Death and Dying. Tavistock, London.

Marteau, L (1970). Good news and bad news, in Religion and Medicine $I$ ed $\mathrm{H}$ Melinsky, p 108. SCM, London.

Quoist, M (1971). Christ is Alive. Gill and Macmillan, Dublin.

Revans, R W (1964). Standards for Morale. OUP, London.

Revans, R W (1970). Structures and Obstructions in Religion and Medicine $I$ ed $\mathrm{H}$ Melinsky, $\mathrm{p}$ 93, SCM, London.

\section{Commentary} C M Fletcher Professor of Clinical Epidemiology,
Royal Postgraduate Medical School, London

Dr Michael Wilson has cogently argued the need for better communication between doctors and patients when approaching death. I wish to consider briefly five practical questions.

\section{Why don't we talk?}

There seem to be four reasons. The first is that we are accustomed to treating our patients successfully with the increasingly powerful tools that medical science has placed in our hands. We tend to be so busy doing this in hospital that we resent the challenge of turning aside to help our failures. This 'action-orientation', which gives all forms of communication a low priority in our scale of values, is particularly inhibitory when there is little that we can do in physical terms. We tend, as Michael
Wilson has said, to pass by the end of the bed, with $\stackrel{\mathbb{Q}}{2}$ an embarrassed nod or a brief word of unconvincing encouragement, to a detailed discussion of the next $\overrightarrow{\bar{\partial}}$. recovering patient, thereby increasing the loneliness and the sense of neglect of the dying. The second is $\overrightarrow{\vec{A}}$ that talking to the dying is costly in time and is emotionally demanding. Cramond (1970) considers that 'any one therapist [he is speaking as a psychia- $\frac{O}{\bar{c}}$ trist] cannot or should not be in such an intense $\frac{\text { क }}{\vec{D}}$ relationship with more than two dying patients at $\stackrel{\mathbb{2}}{\circ}$ any one time'. Thirdly, we have little or no training क to fit us to deal with the many complex issues, $\overrightarrow{0}$ emotional and spiritual, presented by communication with the dying. Finally, in spite of, or even $\vec{\omega}$ because of our close daily acquaintance with death, $\frac{\rho}{3}$ we tend in self protection to look upon it as some- $\bar{\Phi}$ thing which happens to patients and not to ourselves, something from which we want to keep ourselves separate. But no one can give support $\vec{\infty}$ and comfort to the dying until he himself is fully reconciled to his own inevitable death.

\section{When should we talk?}

The simplest answer is 'when our patient wants us ov to talk', but he must be helped. Left without encouragement, he may never ask or may not be willing to unburden his fears until or unless we have obtained a close relationship and can provide an opening. We should not delay communication $\stackrel{\circ}{\mathbb{D}}$ unnecessarily. Parkes (1973) described how patients need to be prepared for bad news and be introduced to it gradually. He has found that doctors and nurses tend to underestimate how much time is left for talking to dying patients.

Hinton (1963) emphasizes that 'there are occasions when a patient experiences anguish, ineffectively trying to thrust out the fear that he may die, but yet vaguely aware that he may need to accept the possibility. Leading the patient into talking of this, and not denying the situation, enables an adjustment to take place with less distress.'

The opportunity may arrive at the end of a careful $\frac{D}{0}$ examination; it may be given by just sitting and waiting in silence or by a simple question such as, $N$ 'Perhaps you have been wondering how seriously $N$ ill you are?', or 'I expect you are pretty worried by this illness?' Whenever it is done, the opportunity 0 should be given since many patients who are dying recognize this but have to face this possibility alone, $O$ in hospital. It is quite wrong, as Michael Wilson has $\stackrel{\oplus}{\mathscr{D}}$ emphasized, that they should be isolated from the comfort of their families at this time.

Not all patients wish to discuss or recognize their $\frac{O}{\pi}$ coming death and we must respect their reticence. $\frac{?}{\overparen{D}}$ We have to remember that the patient's family may $\stackrel{\mathbb{2}}{\square}$ be as distressed as the patient, with feelings of guilt, fear, or resentment. Time must be given to help 8 them too so that they may be better able to help the dying patient. 